\title{
Correction to: Plastics of the Future? The Impact of Biodegradable Polymers on the Environment
}

\author{
Leicheng Zhao, Lili Rong, Longfei Zhao, Jintao Yang, Lei Wang, \\ and Hongwen Sun
}

\section{Correction to:}

Chapter "Plastics of the Future? The Impact

of Biodegradable Polymers on the Environment"

in: Defu He and Yongming Luo (eds.), Microplastics

in Terrestrial Environments - Emerging Contaminants

and Major Challenges, Hdb Env Chem, https://doi.org/10.1007/698_2020_462

This chapter was inadvertently published with three errors, which have now been corrected as follows:

- Caption of Table 3 has been updated to read as: "Ecological effects of completely biodegradable plastics. Reused with permission from [21]"

- Footnote has been added to the heading of Sect. 3.3 ("The Ecological Effect to ...") as follows: "Parts of this text are reused with permission from [21]"

- The references [21] (English version) and [34] (German version) refer to the same article. Therefore, now the reference [34] has been updated as reference [21] throughout the chapter, and the other succeeding references starting from reference [35] have been renumbered accordingly.

\footnotetext{
The updated online version of this chapter can be found at: https://doi.org/10.1007/698_2020_462
} 